Arq. Bras. Med. Vet. Zootec., v.70, n.2, p.457-462, 2018

\title{
Ocorrência da infecção por Campylobacter fetus subsp. venerealis e Tritrichomonas foetus em búfalos no estado de Pernambuco, Brasil
}

\author{
[Infection occurrence of Campylobacter fetus subsp . venerealis and Tritrichomonas foetus in \\ buffaloes in the state of Pernambuco, Brazil]
}

\author{
J.M. Borges ${ }^{1}$, L.B.F. Soares ${ }^{1}$, B.P. Silva ${ }^{1}$, A.A. Macedo ${ }^{2}$, J.M.B. Oliveira ${ }^{2}$, J.W. Pinheiro Júnior ${ }^{3}$ \\ ${ }^{1}$ Aluno de pós-graduação - UFRPE/UAG - Garanhuns, PE \\ ${ }^{2}$ Aluno de pós-graduação - UFRPE - Recife, PE \\ ${ }^{3}$ Universidade Federal Rural de Pernambuco - UFRPE - Recife, PE
}

\begin{abstract}
RESUMO
Objetivou-se com estudo determinar a ocorrência da infecção por Campylobacter fetus subsp. venerealis e Tritrichomonas foetus em búfalos no estado de Pernambuco, Brasil. Foram coletadas 133 amostras biológicas (muco cervicovaginal e raspado prepucial) de animais, procedentes de oito propriedades, de diferentes regiões do estado. O material biológico coletado foi transferido para solução salina tamponada (PBS) e, posteriormente, inoculado em meios de transporte específicos, Lander para diagnóstico de $C$. fetus subsp. venerealis e Diamond para T. foetus. Para o diagnóstico das infecções por Campylobacter fetus subsp. venerealis e Tritrichomonas foetus, as amostras foram submetidas à reação em cadeia da polimerase (PCR) e cultivadas em meio ágar Columbia acrescido de antibiótico e Diamond, respectivamente. Para pesquisa de C. fetus subsp. venerealis, observou-se uma ocorrência de $1,8 \%$ (2/113) de animais positivos no exame microbiológico com confirmação pela PCR. Em relação à procedência, observou-se que $100 \%$ das amostras positivas pertenciam a dois machos do mesmo rebanho. Nenhum animal foi positivo na pesquisa de $T$. foetus. Este é o primeiro registro da infecção por $C$. fetus subsp. venerealis em búfalos no Brasil. Apesar da baixa ocorrência, recomenda-se adoção de medidas de controle, com o intuito de se evitar a disseminação do agente para outros rebanhos.
\end{abstract}

Palavras-chave: Bubalus bubalis, campilobacteriose genital bovina, tricomonose genital bovina

\begin{abstract}
The objective this study was to determine the occurrence of infection with Campylobacter fetus subsp. venerealis and Tritrichomonas foetus in buffaloes in the State of Pernambuco, Brazil. Biological samples were collected (cervico vaginal mucus and shaved prepucial) of 113 animals, coming from 8 properties in different regions of the state. The biological material collected was transferred into phosphate buffered saline (PBS) and inoculated in the specific transport, Lander for diagnosis of C. fetus subsp. venerealis and Diamond for T. fetus subsequently. For the diagnosis of infection by Campylobacter fetus subsp. venrealis and Tritrichomonas foetus the samples were submitted to Polymerase Chain Reaction (PCR) grown in Columbia agar plus antibiotics and Diamond, respectively. There was an occurrence of $1.8 \%$ (2/113) of positive animals in the microbiological examination with confirmation by PCR, for C. fetus subsp. venerealis. We observed that $100 \%$ of positive samples were from two (2) males from the same herd. No animals were positive for $\mathrm{T}$. foetus. This is the first report of infection with C. fetus subsp. venerealis in buffaloes in Brazil. Despite rare occurrence, control measures are recommended in order to prevent the spread of the agent to other herds.
\end{abstract}

Keywords: Bubalus bubalis; bovine genital campylobacteriosis; bovina genital

Recebido em 7 de fevereiro de 2017

Aceito 23 de fevereiro de 2017

E-mail: jonas_borges1@hotmail.com 


\section{INTRODUÇÃO}

Campylobacter fetus subsp. venerealis e Tritrichomonas foetus são agentes causadores da campilobacteriose genital bovina (CGB) e tricomonose genital bovina (TGB), respectivamente (Givens, 2006). Esses patógenos podem ocasionar perdas reprodutivas e, consequentemente, prejuízos para o setor pecuário (Junqueira e Alfieri, 2006).

Estudos epidemiológicos indicam a ocorrência de CGB em rebanhos bubalinos (Serrano et al., 1984; Jacobo et al., 2007; Cipolini et al., 2009). Em relação à TGB, existem poucos relatos na literatura. Na Argentina, foi realizado um estudo com 151 búfalos, mas não foi detectada a presença de $T$ foetus no rebanho bubalino (Jacobo et al., 2007).

A forma de transmissão do Campylobacter fetus subsp. venerealis e Tritrichomonas foetus é direta, em que o macho infectado transmite o agente pela monta natural para as fêmeas susceptíveis (Carvalho e Rodrigues, 2006; Alves et al., 2011). As fêmeas infectadas podem transmitir o agente para outro macho susceptível, completando-se, assim, a cadeia de transmissão (Pellegrin, 2002; Campero e Cobo, 2006). É importante destacar que a inseminação artificial com sêmen contaminado e fômites contaminados utilizados durante o procedimento pode infectar as fêmeas (Eaglesome e Garcia, 1997; Campero e Cobo, 2006).

Os machos são considerados como reservatórios, não apresentam sinais clínicos e transmitem o agente por longos períodos (Gomes e Fernandes, 2006; Spósito Filha e Oliveira, 2009). Os agentes situam-se na cavidade prepucial e depois colonizam as criptas prepuciais, onde se estabilizam, determinando uma infecção crônica assintomática (Eaglesome e Garcia, 1997; Lage e Leite, 2000).

Nas fêmeas, os agentes colonizam a mucosa genital, principalmente vagina $\mathrm{e}$ útero $\mathrm{e}$ provocam lesões como a vaginite moderada com descarga mucopurulenta, uma endometrite discreta e a infertilidade transitória, que pode progredir para salpingite e cervicite e, por conseguinte, levar à interrupção da gestação e ao aborto (Pellegrin et al., 2002, , Mardones et al., 2008; Cobo et al., 2011). Na TGB, pode ocorrer, em alguns casos, maceração fetal e piometra (Felleisen, 1999).

Considerando que esses agentes podem ocasionar perdas reprodutivas na espécie bubalina e que poucas pesquisas foram realizadas com essa espécie, objetiva-se com este estudo determinar a ocorrência da infecção por C. fetus subsp. venerealis e $T$. foetus em búfalos no estado de Pernambuco, Brasil.

\section{MATERIAL E MÉTODOS}

A realização da pesquisa foi aprovada na Comissão de Ética em Uso de Animais (Ceua) da Universidade Federal Rural de Pernambuco, com a licença número 043/2015.

Para determinar a amostragem para o estudo de ocorrência, foi considerada uma população de 9.200 búfalos no estado de Pernambuco (Produção..., 2014) e uma prevalência esperada de 1,8\% para Campylobacter fetus subsp. venerealis e 6,6\% para Tritrichomonas foetus em bovinos no estado de Pernambuco (Oliveira et al., 2015), com intervalo de confiança de $95 \%$ e erro estatístico de 5\%. Com esse parâmetro, foi determinada uma amostragem mínima de 33 bubalinos para pesquisa de C. fetus subsp. venerealis e 100 bubalinos para $T$. foetus.

A escolha das propriedades foi realizada por conveniência não probabilística. Nas propriedades, foram coletadas amostras de machos e fêmeas em idade reprodutiva, com repouso sexual de, no mínimo, sete dias. Nas propriedades visitadas, o manejo reprodutivo adotado era do tipo monta natural, em que os machos permanecem com as fêmeas durante todo o ano. Em relação às fêmeas, não havia histórico de repetição de cio e aumento do intervalo entre parto, com relato de aborto no terço final da gestação somente em duas propriedades.

Para a pesquisa, foram coletadas amostras biológicas de 113 animais, sendo 106 fêmeas e sete machos, procedentes de oito propriedades localizadas em seis municípios de diferentes regiões do estado de Pernambuco, sendo Zona da Mata Sul (cinco) e no Agreste (três).

Para coleta do material biológico nos machos, realizou-se a contenção; em seguida, o corte dos pelos do óstio prepucial, a limpeza com álcool 
$70^{\circ}$ e a secagem com papel- toalha. A coleta foi realizada pela técnica de raspagem do prepúcio, utilizando-se raspadores específicos.

Nas fêmeas, efetuou-se a limpeza da região vulvar com álcool $70^{\circ}$ e secagem com papeltoalha. Para a coleta do muco cervicovaginal, utilizaram-se pipetas de infusão acopladas a seringas de $20 \mathrm{~mL}$ esterilizadas.

Após a coleta, o esmegma e o muco cervicovaginal foram colocados em tubos tipo Falcon, esterilizado com $5 \mathrm{~mL}$ de solução salina tamponada (PBS), pH 7,0. Posteriormente, as amostras foram transferidas, em um volume de $1 \mathrm{~mL}$ do PBS, para os meios de transporte específicos, sendo Lander para diagnóstico de $C$. fetus subsp. venerealis e Diamond para T. foetus.

Para o cultivo de C. fetus subsp. venerealis, as amostras no meio Lander foram incubadas em jarras de microaerofilia a $37^{\circ} \mathrm{C}$, em estufa microbiológica, por $72 \mathrm{~h}$.

Após esse período, as amostras do meio Lander foram semeadas em ágar Columbia (Difco®), adicionado de $7 \%$ de sangue equino desfibrinado e suplemento seletivo Skirrow (Merck ${ }^{\circledR}$ ), sendo incubadas novamente em jarras de microaerofilia por até 72 horas. Nesse período, procedeu-se a leituras das placas com 24, 48 e 72 horas, para observação do crescimento bacteriano, identificação e análise das características fenotípicas das colônias. Para análise das características morfotintoriais, realizou-se a coloração de Gram (Quinn et al., 2005). As colônias suspeitas foram submetidas à reação em cadeia da polimerase.

Para o cultivo de Tritrichomonas foetus, as amostras no meio Diamond foram incubadas em estufa microbiológica a $37^{\circ} \mathrm{C}$, realizando-se leituras nos intervalos de 24, 48, 72 horas.

Para a leitura, as lâminas foram preparadas retirando-se alíquotas de $40 \mu \mathrm{L}$, após homogeneização das amostras, para identificação do agente em microscópio de contraste de fase com aumento de 400x (Jacobo et al., 2007).

A extração de DNA foi feita a partir do PBS coletado, utilizando-se o kit comercial "Wizard ${ }^{\circledR}$ Genomic DNA Purification Kit” (Promega $\left.{ }^{\circledR}\right)$, de acordo com o protocolo do fabricante. Após as extrações dos DNAs, as reações de amplificação do material genômico para C. fetus subsp. venerealis foram realizadas com os oligonucleotídeos VenSF $\left(5^{\text {ee }}\right.$ CTTAGCAGTTTGCGATATTGCCATT3 $\left.{ }^{\text {ee }}\right)$ VenSR

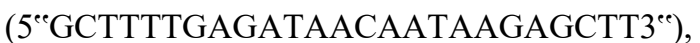
de acordo com o protocolo estabelecido por Hum et al. (1997).

$\mathrm{Na}$ reação de T. foetus, utilizaram-se os oligonucleotídeos TFR3 ( $5^{\mathrm{e}} \mathrm{CGGGTCTTCCTATATGAGACAGAACC3)}$ e TFR4 (5 $5^{\text {ee }}$ CTGCCGTTGGATCAGTTTCGTTAA3 ${ }^{\circ e}$ ), de acordo com o protocolo estabelecido por Felleisen (1997). Para toda reação, foram utilizados controles positivos e negativos. O produto amplificado foi detectado por eletroforese em gel de agarose a $2 \%$, corado com Blue Green (LGCbio) e visualizado com a utilização de luz ultravioleta e fotodocumentado.

\section{RESULTADOS}

Para pesquisa de C. fetus subsp. venerealis, observou-se uma ocorrência de 1,8\% (2/113; I.C. 0,2 - 6,2\%) de animais positivos no exame microbiológico com confirmação pela PCR. Em relação à procedência, observou-se que $100 \%$ das amostras positivas pertenciam a dois machos do mesmo rebanho, com idade superior a cinco anos. Nenhum animal foi positivo para $T$. foetus.

\section{DISCUSSÃO}

Este é o primeiro registro da infecção por $C$. fetus subsp. venerealis em búfalos no Brasil. Em bubalinos, a prevalência relatada em outros estudos varia de 0,6\% a 17\% (Serrano et al., 1984; Modulo et al., 1997; Jacobo et al., 2007; Cipolini et al., 2009). Essa variação pode ser decorrente do delineamento amostral, dos meios de cultivo utilizados para o transporte do material biológico, das técnicas empregadas para o diagnóstico e dos diferentes tipos de manejo higiênico-sanitário e reprodutivo adotados nas propriedades.

A ocorrência observada neste estudo é baixa quando comparada a estudos realizados com a espécie bovina no Brasil, já que a média de prevalência encontrada é de 31,2\% (Pellegrin et al., 2002; Stynen et al., 2003; Rocha et al., 2009; 
Leal et al., 2012). Entretanto, Oliveira et al. (2015) determinaram uma prevalência de 1,8\% (7/333) para infecção por C. fetus subsp. venerealis em fêmeas bovinas no estado de Pernambuco. Dessa forma, acredita-se que a prevalência para essa infecção, nos rebanhos bovinos e bubalinos do estado de Pernambuco, seja realmente baixa.

Apesar de a ocorrência ser considerada baixa, destaca-se que os animais podem servir como disseminadores do agente dentro do rebanho e também para outros rebanhos, visto que é comum na região o empréstimo de animais e a compra e venda de animais sem o devido controle sanitário. Neste estudo, não foi detectada a ocorrência da infecção por C. fetus subsp. venerealis em fêmeas. É importante ressaltar que, na única propriedade em que foram diagnosticados os machos positivos para ocorrência desse agente, não foi possível realizar a coleta de muco cervicovaginal, uma vez que as fêmeas desse rebanho estavam na fase final de gestação.

Destaca-se que a forma de transmissão do agente é direta, em que o macho infectado transmite o agente pela monta natural para as fêmeas susceptíveis (Alves et al., 2011). Alguns fatores relacionados à epidemiologia da doença são diferenciados de acordo com o sexo, visto que os machos são considerados como reservatórios por não apresentarem sinais clínicos. Observa-se maior frequência da infecção por esse patógeno nos touros mais velhos em função do aumento do tamanho e do número das criptas no epitélio do prepúcio (Dekeyser, 1986; Pellegrin et al, 2002).

Apesar de não terem sido diagnosticadas fêmeas positivas neste estudo, deve-se levar em consideração que as fêmeas infectadas podem transmitir o agente para outro macho susceptível, completando, assim, a cadeia de transmissão do C. fetus subsp. venerealis (Alves et al., 2011). Dessa forma, faz-se necessário um acompanhamento nos índices reprodutivos dos rebanhos bubalinos, uma vez que esse agente pode ocasionar perdas reprodutivas, tais como: infertilidade temporária, retorno ao cio, salpingite e aborto (Lage e Leite, 2000; Cobo et al., 2011).

Durante as coletas, observaram-se algumas particularidades no manejo higiênico-sanitário e reprodutivo dos rebanhos que favorecem a disseminação do C. fetus subsp. venerealis, tais como: compra de animais de outras propriedades sem atestado sanitário, utilização de monta natural, ausência de estação de monta. Os fatores de risco associados à CGB são prática de empréstimo de reprodutores para a cobertura de vacas em diferentes rebanhos (Mardones et al., 2008), acesso de reprodutores procedentes de outras propriedades ao rebanho e o uso de pastagens compartilhadas (Rojo-Montejo et al., 2010, Jimenez et al., 2011), aquisição de animais de rebanhos onde não se tenha o conhecimento do status sanitário (Mai et al., 2013) e rebanhos acima de 100 animais (Oliveira et al., 2015).

Neste estudo, não foi possível identificar a ocorrência da infecção por $T$. foetus, resultado semelhante ao estudo conduzido por Jacobo et al. (2007) em búfalos na Argentina. Estudos com um maior número de rebanhos devem ser realizados, visto que a TGB em búfalos já foi notificada à Organização Mundial de Saúde Animal (OIE) no estado de Minas Gerais, Brasil, em 2009 (Organização..., 2015).

Resultados falsos negativos para pesquisa de $T$. foetus podem ocorrer devido a uma baixa quantidade de parasito durante a coleta. Outro ponto que deve ser destacado é que, neste estudo, só foi possível realizar uma única coleta nas propriedades. Destaca-se que, para o diagnóstico de Campylobacter fetus subsp. venerealis e Tritrichomonas foetus, os animais só devem ser considerados negativos com a realização de três exames consecutivos. De acordo com OrtegaMora et al. (1996), um único teste pode ser adequado para o diagnóstico de rebanho quando um ou mais touros estão infectados, mas, para exame individual de um touro, três exames negativos são necessários para assegurar que $o$ animal não esteja infectado com $T$. foetus.

A CGB e a TGB são enfermidades pouco conhecidas pelos médicos veterinários que atuam a campo, e esse fato, associado à ausência de uma rede de laboratórios veterinários aptos a realizarem o diagnóstico de forma padronizada, dificulta determinar a real prevalência dessas infecções.

O controle das enfermidades deve ser realizado mediante a identificação dos fatores de risco. Dessa forma, recomenda-se a eliminação dos 
touros infectados, a introdução de inseminação artificial (IA), a adoção de uma estação de monta e o repouso sexual das fêmeas por 90 dias. O monitoramento dos rebanhos, mediante a realização rotineira do diagnóstico das enfermidades, também pode contribuir para o controle (Pellegrin et al., 2002; Spósito Filha, 2009; Oliveira, 2015; Molina et al., 2013).

\section{CONCLUSÃO}

Este é o primeiro registro da infecção por $C$. fetus subsp. venerealis em búfalos no Brasil. Apesar da baixa ocorrência, recomenda-se que medidas de controle sejam adotadas, com o intuito de evitar a disseminação do agente para outros rebanhos.

\section{REFERÊNCIAS}

ALVES, T.M.; STYNEN, A.P.R.; MIRANDA, K.L.; LAGE, A.P. Campilobacteriose genital bovina e tricomonose genital bovina: epidemiologia, diagnóstico e controle. Pesqui. Vet. Bras., v.31, p.336-344, 2011.

CAMPERO, C.; COBO, E. Tritrichomonas foetus: patogénesis de la mortalidad embrionaria/fetal, caracterización de antígenos vacúnales y respuesta inmune inducida. Rev. Méd. Vet., v.87, p.47-56, 2006.

CARVALHO, D.V.; RODRIGUES, A.F.S.F. Tritrichomonas foetus (Riedmuller,1928) (Protista, Trichomonadidae) e a implicação na pecuária do Brasil. CES Rev., v.6, p.113-132, 2006.

CIPOLINI, M.F.; JÁCOBO, R.A.; STORANI, C.A. et al. Campylobacteriosis en hembras bubalinas, Campylobacteriosis en búfalas. Rev. Vet., v.20, p.130-131, 2009.

COBO, E.R.; CORBEIL, L.B.; BONDURANT, R.H. Immunity to infections in the lower genital tract of bulls. J. Reprod. Immunol., v.89, p.55-61, 2011.

DEKEYSER, P.J. Bovine genital campilobacteriosis. In: MORROW, D.A. (Ed.). Current therapy. Philadelphia: W.B. Saunders Company, 1986. p.263-266.

EAGLESOME, M.D.; GARCIA, M.M. Disease risks to animal health from artificial insemination with bovine semen. Rev. Sci. Technol., v.16, p.215-225, 1997.
FELLEISEN, R.S.J. Comparative sequence analysis of $5 \pm 8 \mathrm{~S}$ rRNA genes and internal transcribed spacer (ITS) regions of trichomonadid protozoa. Parasitology, v.115, p.111-119, 1997.

FELLEISEN, R.S.J. Host-parasite interaction in bovine infection with Tritrichomonas foetus. Microbes Infec., v.1, p.807-816, 1999.

GIVENS, M.D. A clinical, evidence-based approach to infectious causes of infertility in beef cattle. Theriogenology, v.66, p.648-654, 2006.

GOMES, M. J. P.; FERNANDES, J. C. T.; Campilobacteriose Genital Bovina. Departamento de Patologia Clínica Veterinária, Setor de Bacteriologia da Faculdade de Veterinária UFRGS, Porto Alegre -RS, 2006

HUM, S.; QUINN, K.; BRUNNER, J. Evaluation of a PCR assay for identification and differentiation of Campylobacter fetus subspecies. Aust. Vet. J., v.75, p.827-831, 1997.

JACOBO, R.A.; STORANI, C.A. et al. Resultados preliminares del diagnóstico de campylobacteriosis y trichomonosis en búfalos del nordeste argentino. Rev. Vet., v.18, p.130132, 2007.

JIMENEZ, D.F.; PEREZ, A.M.; CARPENTER, T.E; MARTINEZ, A. Factors associated with infection by Campylobacter fetus in beef herds in the Province of Buenos Aires, Argentina. Prev. Vet. Med., v.101, p.157-162, 2011.

JUNQUEIRA, J.R.C.; ALFIERI, A.A. Reproductive failures in beef cattle breeding herds with emphasis for infectious causes. Ciênc. Agrár., v.27, p.289-298, 2006.

LAGE, A.P.; LEITE, R.C. Campilobacteriose genital bovina (Vibriose). Pecu. Corte, v.10, p.50-54, 2000.

LEAL, D.R.; FERNANDES, G.O.; GOUVEIA, F.F. et al. Prevalência da campilobacteriose e da tricomonose genitais bovinas no Distrito Federal e em seu entorno. Rev. Bras. Reprod. Anim., v.36, p.256-259, 2012.

MAI, H.M.; IRONS, P.C.; KABIR, J.; THOMPSON, P.N. Herd-level risk factors for Campylobacter fetus infection, Brucella seropositivity and within-herd seroprevalence of brucellosis in cattle in northern Nigeria. Prev. Vet. Med., v.111, p.256-267, 2013. 
MARDONES, F.O.; PEREZ, A.M.; MARTÍNEZ A.; CARPENTER, T.E. Risk factors associated with Tritrichomonas foetus infection in beef herds in the Province of Buenos Aires, Argentina, Vet. Parasitol., v.153, p.231-237, 2008.

MODULO, J.R.; BISPING, W.; LOPES, C.A.M. et al. Characterization of Campylobacter in genitals of buffalo bulls. Indian J. Anim. Sci., v.67, p.682-683, 1997.

MOLINA, L.; PEREA, J.; MEGLIA, G. et al. A. Spatial and temporal epidemiology of bovine trichomoniasis and bovine genital campylobacteriosis in La Pampa province (Argentina). Prev. Vet. Med., v.110, p.388-394, 2013.

OLIVEIRA, J.M.; SILVA, G.M.; BATISTA FILHO, A.F. et al. Prevalence and risk factors associated with bovine genital campylobacteriosis and bovine trichomonosis in the state of Pernambuco, Brazil. Trop. Anim. Health Prod., v.47, p.549-555, 2015.

ORGANIZAÇÃO Mundial de Saúde Animal, 2015. Available in: $<$ http://www.oie.int/wahis_2/public/wahid.php/D iseaseinformation/diseasehome>. Accessed in: Jun. 2016

ORTEGA-MORA, L.M.; PEREIRA BUENO, J.; ROJO-VASQUEZ, F.A. Tricomonosis bovina genital bovina (I). Med. Vet., v.13, p.7-13, 1996.

PELLEGRIN, A.O.; LAGE, A.P.; SERENO, J.B. et al. Bovine Genital Campylobacteriosis in Pantanal, State of Mato Grosso do Sul, Brazil. Rev. Elev. Med. Vet. Pays Trop., v.55, p.169173, 2002.
PRODUÇÃO Pecuária. [Rio de Janeiro]: IBGE, $2014 . \quad$ Disponível em: $<$ http//www.ibge.gov.br/Producao_Pecuaria/Prod ucao_da_Pecuaria

Municipal/2014/ppm2014.pdf./>. Acessado em: 12 mar. 2016

QUINN, P.J. et al. Microbiologia veterinária e doenças infecciosas. Porto Alegre: Artmed, 2005. p.415.

ROCHA, F.S.; JESUS, V.L.T.; TORRES, H.M. et al. Investigação de Campylobacter fetus e Tritrichomonas foetus na mucosa prepucial de touros da região do Médio Paraíba, RJ. Ciênc. Rural, v.39, p.1586-1589, 2009.

ROJO-MONTEJO, S. et al. La tricomonosis y la campilobacteriosis genital bovina: dos enfermedades importantes en el diagnóstico del fallo reproductivo en explotaciones con monta natural. In: congreso internacional anembe de medicina bovina. 15, 2010. anais... granada, espanha. 2010.

SERRANO, G.; VARGAS DIAZ, M.; CLAVIJO, A. Campylobacteriosis (Vibriosis) en rodeos bubalinos de Venezuela. Vet. Trop., v.8, p.95-111, 1984.

SPÓSITO FILHA, E.; OLIVEIRA; S.M. Tricomonose bovina. Biológico, v.71, p.9-11, 2009.

STYNEN, A.P.R.; PELLEGRIN, A.O.; FÓSCOLO, C.B. et al. Campilobacteriose genital bovina em rebanhos leiteiros com problemas reprodutivos da microrregião de Varginha - Minas Gerais. Arq. Bras. Med. Vet. Zootec., v.55, p.766-769, 2003. 